\title{
Review Article \\ Spinal Fusion in the Next Generation: Gene and Cell Therapy Approaches
}

\author{
Marta Barba, ${ }^{1}$ Claudia Cicione, ${ }^{1}$ Camilla Bernardini, ${ }^{1}$ Vincenzo Campana, ${ }^{2}$ \\ Ernesto Pagano, ${ }^{2}$ Fabrizio Michetti, ${ }^{1,3}$ Giandomenico Logroscino, ${ }^{2}$ and Wanda Lattanzi ${ }^{1,3}$ \\ ${ }^{1}$ Institute of Anatomy and Cell Biology, Università Cattolica del Sacro Cuore, Largo Francesco Vito, 1, 00168 Rome, Italy \\ ${ }^{2}$ Departement of Orthopaedics and Traumatology, Università Cattolica del Sacro Cuore, Largo Agostino Gemelli, 8, \\ 00168 Rome, Italy \\ ${ }^{3}$ Latium Musculoskeletal Tissue Bank, Largo Francesco Vito, 1, 00168 Rome, Italy
}

Correspondence should be addressed to Claudia Cicione; claudia.cicione@libero.it and

Wanda Lattanzi; wanda.lattanzi@rm.unicatt.it

Received 30 August 2013; Accepted 28 October 2013; Published 28 January 2014

Academic Editors: H.-Y. Lin and H. Park

Copyright (c) 2014 Marta Barba et al. This is an open access article distributed under the Creative Commons Attribution License, which permits unrestricted use, distribution, and reproduction in any medium, provided the original work is properly cited.

\begin{abstract}
Bone fusion represents a challenge in the orthopedics practice, being especially indicated for spine disorders. Spinal fusion can be defined as the bony union between two vertebral bodies obtained through the surgical introduction of an osteoconductive, osteoinductive, and osteogenic compound. Autogenous bone graft provides all these three qualities and is considered the gold standard. However, a high morbidity is associated with the harvest procedure. Intensive research efforts have been spent during the last decades to develop new approaches and technologies for successful spine fusion. In recent years, cell and gene therapies have attracted great interest from the scientific community. The improved knowledge of both mesenchymal stem cell biology and osteogenic molecules allowed their use in regenerative medicine, representing attractive approaches to achieve bone regeneration also in spinal surgery applications. In this review we aim to describe the developing gene- and cell-based bone regenerative approaches as promising future trends in spine fusion.
\end{abstract}

\section{Introduction}

Spine fusion is a surgical technique used to join two or more vertebrae and to stabilize the corresponding spine segment. It is frequently used to treat traumatic and degenerative spine disease, such as scoliosis, kyphosis, fractures, dislocations, spondylolisthesis, and intervertebral disc diseases [1-3].

The fusion is achieved through stabilization systems adding supplementary bone tissue and/or bone substitutes between adjacent vertebrae, as to enhance bone healing and to achieve faster stability. Three types of bone grafts can be classified (Table 1): (i) autografts: the donor is the same as the receiver; (ii) allografts: the donor is human but is different from the receiver; (iii) xenografts: the donor is from different animal species (heterologous graft).

The process of spinal fusion requires three essential characteristics: osteoconductivity, osteoinductivity, and osteogenicity. Autologous bone graft has all these properties, provides an ideal material for spine fusion, and has long been considered the gold standard for fusion procedures. A significant morbidity is inherently associated with the harvest procedure, as a bone defect is created, requiring also prolonged surgical duration $[4,5]$. Moreover, the limited availability of autologous bone is a significant limitation.

Allograft bone is routinely used as an alternative to autogenous bone to avoid complications related to donor site morbidity and availability. Nonetheless, concerns about immunogenicity and infectious disease transmission are ascribed to its use $[6,7]$.

Xenografts represent an alternative strategy, employed more frequently in dental surgery than in orthopedic surgery. In theory, the principal disadvantage of heterologous graft is the high level of antigenicity. Partially deproteinated and partially defatted heterologous bone (Kiel bone or Oswestry bone) exhibits a significantly reduced antigenicity and minimal immune response, but the denaturation process destroys 
TABLE 1: Bone substitutes resuming.

\begin{tabular}{lccccc}
\hline Category & Bone substitute & Osteoinduction & Osteoconduction & Strength & Resorbability \\
\hline Biological & Autografts & + & + & + & + \\
Biological & Allografts & $+/-$ & + & + & + \\
Biological & Xenografts & - & + & $+/-$ & + \\
Synthetic & Calcium-based & - & $+/-$ & $+/-$ \\
Synthetic & Polymer-based & - & & + \\
\hline
\end{tabular}

$+:$ the material has this property.

- : the material does not have this property.

$+/-$ : the material has intermediate properties.

the matrix proteins, damaging the osteoinductive properties. Also, the risk of zoonoses for diseases such as BSE (bovine spongiform encephalopathy) or PERV (porcine endogenous retroviruses) has been often discussed [8].

These and other difficulties with bone grafts have been driving the intensive research efforts that have been spent during the last decades to develop new approaches and technologies for successful spine fusion. On this regard, synthetic bone substitutes have been proposed as valuable alternative options (Table 1), based on osteoconductive/osteoinductive biomaterials owing the ability (i) to generate a microenvironment which induces the cellular growth; (ii) to recruit bone precursor cells (osteoconductivity) in the area surrounding the implant site; (iii) to induce cell proliferation and differentiation required for the osteogenic process (osteoinductivity) [9]. New calcium and phosphate-based substitutes have been developed, leading to the generation of biomaterials known as "bioceramics." Often a mixture of hydroxyapatite (HA) and its amorphous phase, the tricalcium phosphate (TCP), is used to obtain bioactive ceramics, which form direct chemical bonds with bone or even with soft tissues of a living organism $[10,11]$.

In recent years, cell and gene therapies have attracted great interest from the scientific community and have shown to represent promising approaches to achieve bone regeneration also in spine surgery. The improved knowledge on adult stem cell biology and of mesenchymal stem cell features allowed their use in regenerative medicine, with particular focus on bone regeneration. In particular, cellbased approaches based on mesenchymal stem cells (MSC) have been widely employed and considered the most effective for bone formation and regeneration in vivo $[12,13]$. In addition, the overwhelming amount of studies that have been investigating the molecular scenario orchestrating osteogenesis and bone healing, provided new osteoinductive molecules to be tested as potential drugs in spine surgery. On the other hand, cell-based gene therapy approaches based on engineered-osteoinductive cells allowed achieving the most convincing results in terms of bone healing and spine fusion in animal models [14-19]. Actually, genetically engineered cells are believed to maintain physiologic doses of a gene product for a sustained period once inoculated into the selected anatomical site, facilitating an efficient bone healing [20].

Taken together, the developing molecular and cellbased bone regenerative approaches may plausibly represent promising future trends in spine fusion and will be reviewed below in detail.

\section{Cell-Therapies for Spinal Fusion}

Mesenchymal stem cells (MSCs) have been widely used as suitable somatic cells to induce bone formation and regeneration. MSCs are multipotent stem cells that are capable of extensive self-renewal, plasticity, and multilineage potential $[21,22]$. These cells are located in the connective stroma of mesenchymal-derived adult organs and tissues; hence they are also named "stromal stem cells" [23]. Strictly defined MSCs are those isolated from bone marrow aspirates (bone marrow-mesenchymal stem cells, BM-MSCs); though, cells displaying high similarities have been found practically in quite any organ comprising a connective stroma including adipose tissue, lung, skeletal muscle, synovial membrane, tendons, and skin, along with antenatal tissues such as umbilical cord, placenta, and amniotic fluid [22, 24-30]. MSCs are easily isolated through adherence selection in vitro and can be further cultured for several passages, without losing their plasticity and self-renewal potential [31]. Upon appropriate in vitro induction, MSCs can be differentiated along the osteogenic lineage [32]. This property has been exploited for cell-based therapy of congenital bone disorders [33, 34]. The feasibility of an MSC-therapy for orthopedic disorders comes also from their immunomodulatory properties, implying their potential use in allogeneic transplantation, preventing graft-versus-host disease [35].

A single clinical trial testing ex vivo expanded autologous BM-MSC for spinal fusion in spine degenerative diseases seems to be open, according to publicly available information (Figure 1; http://www.clinicaltrials.gov/).

In the clinical practice, BM-MSCs are usually harvested from the iliac crest (IC), through an invasive and painful procedure. To limit such donor morbidity issues, vertebral body (VB) bone marrow has been proposed as an alternative source of BM-MSCs. Compared to IC, VB-MSCs are easily isolated from the surgical site and show a higher amount of osteoprogenitor cells $[36,37]$. However, both sources are subjected to a significant decline in stem cell number and proliferative capacities in elderly, when main indications for regenerative medicine approaches are encountered [38]. In addition, the number of MSC in bone marrow is reported to be 1 out of $5000(0.0002 \%)$ total isolated cells [39]. Recently, adipose tissue has been highlighted as an excellent 


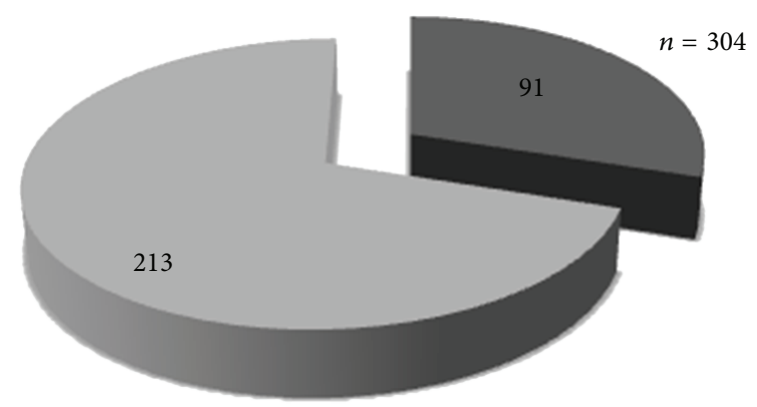

Total

Open

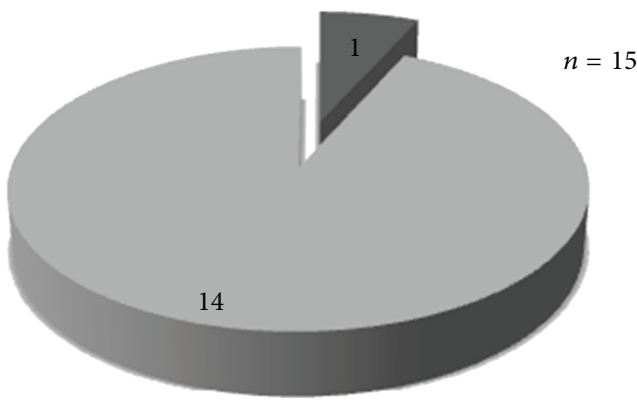

Total

Open

(b) SF Clinical trials with stem cells

(a) SF Clinical trials

Figure 1: Spinal fusion clinical trials. Graphical view of the 304 clinical trials from http://www.clinicaltrials.gov/; 91 of these are open (a). In particular, spinal fusion clinical trials based on stem cell-therapy are 15; 1 of these is open (b).

source of MSCs (namely adipose derived stem cells, ASCs) [40]. In particular, the adipose stromal vascular fraction (SVF) has emerged as a rich and promising source of ASCs [40], displaying extensive plasticity and multilineage differentiation potential [24, 41-44]. BM-MSCs and ASCs share part of their immunophenotype and gene expression profile, which is consistent with their stemness upholding and uncommitted [45-47]. Potentially, great advantages of ASCs over BM-MSCs are suggested by the high plasticity and extended self-renewal capability of these cells and by the abundance of adipose tissue, its surgical accessibility, and its high cellular content. Additionally, adipose tissue is now considered the largest human endocrine organ due to its role in the regulation of cellular functions, through a complex network of endocrine, paracrine, and autocrine signals [48]. There is actually an intense cross-talk between bone and adipose tissue, mediated by proteins endowed with endocrine functions secreted by adipocytes (adipokines) and osteoblasts (osteokines), which may suggest the feasibility of the use of SVF in bone regeneration, also due to the high angiogenicity endowed with the SVF $[49,50]$.

Distinct preclinical studies have tested the effectiveness of the MSCs from different tissue sources, in animal models of spinal fusion, combined with alternative scaffolds, with alternative scaffold, with successful results (Table 2). Most studies transplanted allogeneic cells into immunocompetent recipient animals [51-57].

Several animal studies used either wild type or osteogenic-committed BM-MSCs as possible substitutes of autologous bone-graft, with a good rate of spinal fusion [51-53, 55, 57-63]. The higher rate of spinal fusion has been obtained with culture-expanded BM-MSCs compared to freshly isolated cells [64]. In addition, Nakajima and colleagues [65] assessed that osteodifferentiated MSCs were more efficient in promoting spinal fusion than undifferentiated cells.

Interestingly, ASCs proved to allow bone regeneration in vivo, without the need for ex vivo engineering and/or induction [12]. Also, it has been clearly demonstrated that allogeneic ASCs displays a nonimmunogenic profile in vitro and does not evoke cell-based immunity when implanted in a rat spinal fusion model [66]. Taken together, these data could provide quite convincing proof-of-principle on the potential safeness and efficacy of banked MSCs from healthy donors. Though, the required standards for clinical-grade cell manufacturing (i.e., the current good manufacturing practices, cGMP, guidelines) would be quite hard to be met by the current experimental protocols employed for ASC isolation and culture [67]. However, these problems can be overcome with the development of single-step procedures to treat spinal disorders, by combining freshly harvested SVF and scaffolds $[68,69]$.

Besides MSC, fibroblasts have been proposed as suitable cell types for bone regenerative purposes. In particular, dermal fibroblasts (DF) can be easily isolated from small skin biopsies, with reduced local morbidity, and rapidly expanded in culture. Dermal fibroblasts share significant similarities with MSCs, being considered the skin-derived counterpart, and can be induced rapidly towards the osteogenic lineage $[20,70,71]$. Such features render DF a potentially promising tool for bone formation and regeneration.

\section{Gene Therapies for Spinal Fusion}

Gene therapy approaches are based on the rationale of delivering osteoinductive genes locally to induce bone formation and improve spinal fusion $[15,20,72]$.

Different gene strategies have been proposed and tested as innovative strategies in spinal surgery to increase the osteogenic potential of osteoprogenitor cells and to obtain a higher bone formation rate in vivo. Bone morphogenetic proteins (BMP) represent the best characterized molecules implicated in the osteogenic cascade and have been widely employed to induce bone formation in spinal fusion models [73].

The BMP family is composed of 20 distinct highly conserved secreted proteins, further categorized into multiple 
TABLE 2: Cell-based gene therapy in animal models of spine fusion.

\begin{tabular}{|c|c|c|c|c|}
\hline Fusion site & Specie & Cell treatment & Scaffold & Reference \\
\hline \multicolumn{5}{|c|}{ BM-MSC } \\
\hline $\mathrm{PF}$ & Rat & None & Matrigel & {$[58]$} \\
\hline PLF & Macaque & None & b-TCP & [59] \\
\hline PLF & Goat & None & Ceramics & {$[60]$} \\
\hline PLF & Rabbit & None & CRM & {$[61]$} \\
\hline PLF & Mouse & None & Collagen & {$[62]$} \\
\hline PLF & Rabbit & None & ProOsteon $500 \mathrm{R}$ & {$[51]$} \\
\hline PLF & Rat & None & Ceramic & [63] \\
\hline PLF & Rabbit & None & HA/Collagen & {$[52]$} \\
\hline AIBF & Pig & None & $\mathrm{mPCL} / \mathrm{TCP}$ & {$[53]$} \\
\hline PLF & Rat & Oxysterols & Collagen & {$[74]$} \\
\hline PLF & Rabbit & None & TCP w/wo LIPUS & {$[75]$} \\
\hline $\mathrm{PF}$ & Human & None & b-TCP & {$[76]$} \\
\hline PLF & Rabbit & Hyperbaric $\mathrm{O}_{2}$ & Alginate & {$[77]$} \\
\hline PLF & Rabbit & AdBMP2 & Collagen & [78] \\
\hline PLF & Rabbit & AdBMP2 & None & [79] \\
\hline $\mathrm{PF}$ & Rat & AdBMP7 & None & {$[80]$} \\
\hline PLF & Rat & $\begin{array}{c}\text { LentiBMP2 } \\
\text { AdBMP2 }\end{array}$ & Collagen & {$[81]$} \\
\hline PLF & Rat & LentiBMP2 & Collagen & {$[54]$} \\
\hline PLF & Rabbit & rhBMP2 & Alginate & {$[82]$} \\
\hline PLF & Rabbit & AdSmad-1c & Gelatin & [83] \\
\hline \multicolumn{5}{|c|}{ ASC } \\
\hline PLF & Rat & None & TCP-Collagen & [53] \\
\hline PLF & Rat & None & b-TCP-Collagen & {$[66]$} \\
\hline $\mathrm{PF}$ & Goat & None & PLCL & {$[55]$} \\
\hline PLF & Rabbit & None & nHAC-PLA & {$[84]$} \\
\hline ACIF & Sheep & None & b-TCP & {$[85]$} \\
\hline MLF & Pig & None & PEEK & {$[86]$} \\
\hline PLF & Rat & rhBMP2 & Collagen & {$[87]$} \\
\hline $\mathrm{PF}$ & Mice & rhBMP6 & None & {$[88]$} \\
\hline PLF & Rat & AdBMP2 & Collagen & {$[56]$} \\
\hline VCF & Rat & rhBMP6 & Fibrin & [89] \\
\hline
\end{tabular}

PF: posterior fusion; PLF: posterolateral fusion; AIBF: anterior interbody fusion; AICF: anterior interbody cervical fusion; MLF: multi-level fusion; VCF: vertebral cervical fusion; TCP: tricalcium phosphate; CRM: compression-resistant matrix; HA/Collagen: hydroxyapatite/type 1 collagen; mPCL: medical grade poly ( $\varepsilon$-caprolactone); LIPUS low-intensity pulsed ultrasound, $\beta$-TCP: beta-tricalcium phosphate; PLCL: poly (L-lactide-co-caprolactone); nHAC-PLA: nanohydroxyapatite-collagen/polylactic acid; PEEK: polyetheretherketone.

subgroups according to functional and/or structural features $[90,91]$. BMP play a pivotal role in skeletogenesis during limb development processes. In particular, they increase osteoclastogenesis and induce the osteoblastic commitment of MSC, inhibiting their differentiation along the myoblastic and adipogenic lineages [91-94]. The osteogenic BMP, are BMP2, BMP4 and BMP7 (also known as osteogenic protein1, OP-1). They can induce the differentiation of MSC into both osteochondrogenic lineage cells and osteoblast precursor cells, implicating their essential contribution to both direct and indirect ossification mechanisms occurring in vertebrates [95-97]. A wide number of preclinical studies have demonstrated that these small molecules are capable of inducing ectopic bone formation upon intramuscular implantation and efficient bone healing/regeneration, when delivered on the appropriate scaffold and in the appropriate concentration into a bone defect site $[12,14,98]$. In addition, the use of recombinant human BMP2 (rhBMP2) and BMP7 (rhBMP7) has been approved in both Europe and the United States for selected clinical applications, including lumbar interbody spinal fusion and tibial non-union defects. Nowadays, various genetic engineering approaches are being considered to produce second-generation BMPs, aimed at improving binding affinity to target specific cells, reducing 
sensitivity to natural inhibitors, reducing immunogenicity, and increasing solubility and stability [99].

The main limitation of using recombinant proteins for inducing bone formation in clinical applications is the need for delivery systems that provide a sustained and biologically appropriate concentration of the osteogenic factor at the site of the defect $[12,20]$. The vectors used for gene therapy approaches comprise naked DNA, liposomes, plasmids, and viral vectors [100]. Nonviral vectors are generally safer due to the absence of infectious-related issues. However, they have a low transfection efficiency. The viral vector commonly used in gene therapy approaches for spinal fusion belongs to the adenovirus species. Defective human adenoviruses are indeed suitable gene vectors due to their ability to mediate high-level and short-term gene expression. Although their use implies several disadvantages in view of a potential clinical application [14], adenoviral vectors carrying osteoinductive genes have been successfully used in preclinical spinal fusion models (Table 2). Most studies employed defective adenoviral vectors carrying the BMP2 gene (AdBMP2), either for ex vivo cell transduction $[54,70,78,79,87]$ or for direct percutaneous injection [101]. The chance of spinal fusion increases by using cells for achieving an appropriate local gene delivery. In fact, genetically engineered cells can mediate the local expression of osteoinductive genes in a timeand site-effective manner, thus mimicking the physiologic secretion in vivo. Engineered cell-based therapy approaches resulted in being indeed more efficient than recombinant osteoinductive proteins alone [102, 103]. However, despite the significant evidence of their potential benefit to bone repair, there is, to date, a dearth of convincing clinical trials [104].

With regard to the cell type, Miyazaki and colleagues recently demonstrated that the efficacy of AdBMP2transduced MSC treatment is not related to the tissue source for cell isolation. ASCs and BM-MSCs proved to exert comparable results in a rat spinal fusion model [105]. Adenoviral vectors carrying BMP4 [106], BMP6 [107], and BMP9 [105] were also used for direct injection into the paraspinal musculature, which proved to be effective. Also BMP7 has been tested as a suitable molecule delivered ex vivo in BM-MSC to induce spine fusion [80].

Nonetheless, several contraindications hinder the use of adenoviral vectors in humans, including systemic toxicity, immunization (over 95\% adults have neutralizing antibodies against adenovirus species 5), and low cell selectivity [14].

A lentivirus-based BMP2 vector (lenti-BMP2) has been also tested as a feasible tool to induce stable osteogenic commitment of BM-MSCs in a rat spinal fusion model [81]. Lenti-BMP2 is a specialized retrovirus capable of random integration in the host cell genome. This strategy proved to be more effective than AdBMP2-based cell transduction [54]. However, the possible risks of insertional mutagenesis should be carefully considered when using lentiviral vectors [14].

Recently, a nonviral approach was attempted using nucleofection (i.e., the intranuclear transfection by electroporation) of rhBMP6 in ASCs [89]. The results obtained through this virus-free technology sound encouraging, although the plasmid DNA used in the procedure still retains some inherent bacterial-related toxicity.

Besides BMP, other molecules have been tested for their osteogenic potential in gene therapy approaches for spinal fusion. These included the Nell-like molecule (Nell-1) [108, 109], the LIM mineralization protein (LMP) [20, 110], and the mothers against decapentaplegic homolog 1 (Smad1) [83].

Nell-1 is a heterotrimeric secretory protein thought to be involved in cell growth regulation and differentiation, acting specifically in osteoblasts. Nell-1 is overexpressed in synostotic calvaria of patients affected by sporadic plagiocephaly [111] and is able to induce bone regeneration in rat calvarial defects [112]. Based on the evidence that this gene is more osteoblast specific than BMP, the efficacy of AdNell-1 injection in a rat posterolateral spinal fusion model has been tested with successful results [109].

LMP is an intracellular LIM-domain protein acting as a potent positive regulator of the osteoblast differentiation program, being able to induce the activation of BMPs and downstream signaling pathway $[113,114]$. In humans, three different splice variants are transcribed from the LMPcoding gene (PDZ and LIM domain-7, PDLIM7), named LMP1, LMP2, and LMP3. Both LMP1 and LMP3 induce osteogenic differentiation of mesenchymal progenitors and pre osteoblasts in vitro and bone formation in diverse animal models [12, 20, 80, 89, 104-107, 110, 114-119]. Similar to Nell1 , LMPs in humans are overexpressed in calvarial tissues and cells isolated from synostosis of patients affected by sporadic synostosis, where it possibly plays a pathogenetic role [120]. LMP1 has been used successfully to induce spine fusion in rats and rabbits, upon plasmid transfection and adenoviral vector-mediated delivery, respectively $[110,113]$. Adenoviralmediated ex vivo transduction was also used to overexpress LMP3 in dermal fibroblast in a mouse model of paravertebral ectopic bone formation, resulting in the formation of an overwhelming new bony mass [20].

Finally, another gene therapy approach to spine fusion has been recently performed in a rabbit model, using the Hoxc-8-interacting domain of Smad1. In this case, ex vivo transduction was performed using an adenoviral vector, modified to target specifically BM-MSC in order to improve the efficiency of gene transfer [83].

Overall the genetic engineering strategies proposed so far in spinal orthopedics surgery proved to be extremely effective. Much effort should be further spent in improving the safety of the gene delivery strategies by limiting the toxicity and the immunogenicity and avoiding modification that could lead to genomic instability.

\section{Conclusions}

Despite the improvement of surgical procedures, the research efforts achieved so far did not allow obtaining convincing result to suggest alternative effective methods to replace or at least flank bone grafting. Further studies and clinical trials are foreseen to achieve the goal of improving spinal 
surgery avoiding donor morbidity and overcoming the need for human donors.

\section{Conflict of Interests}

The authors declare that there is no conflict of interests regarding the publication of this paper.

\section{Authors' Contribution}

Marta Barba and Claudia Cicione contributed equally to the paper.

\section{Acknowledgments}

This work was supported by grants to Wanda Lattanzi by the Catholic University (linea D1-2011, 2012) and to Giandomenico Logroscino by the FP7 EC grant OPHIS, 2011-2014 (FP7-NMP-2009-SMALL-3-246373).

\section{References}

[1] M. Etminan, F. P. Girardi, S. N. Khan, and F. P. Cammisa Jr., "Revision strategies for lumbar pseudarthrosis," Orthopedic Clinics of North America, vol. 33, no. 2, pp. 381-392, 2002.

[2] S. D. Boden, "Overview of the biology of lumbar spine fusion and principles for selecting a bone graft substitute," Spine, vol. 27, no. 16, pp. S26-S31, 2002.

[3] A. Minamide, M. Kawakami, H. Hashizume, R. Sakata, and T. Tamaki, "Evaluation of carriers of bone morphogenetic protein for spinal fusion," Spine, vol. 26, no. 8, pp. 933-939, 2001.

[4] J. N. Rawlinson, "Morbidity after anterior cervical decompression and fusion. The influence of the donor site on recovery, and the results of a trial of surgibone compared to autologous bone," Acta Neurochirurgica, vol. 131, no. 1-2, pp. 106-118, 1994.

[5] S. S. Liao, K. Guan, F. Z. Cui, S. S. Shi, and T. S. Sun, "Lumbar spinal fusion with a mineralized collagen matrix and rhBMP-2 in a rabbit model," Spine, vol. 28, no. 17, pp. 1954-1960, 2003.

[6] S. N. Khan, F. P. Cammisa Jr., H. S. Sandhu, A. D. Diwan, F. P. Girardi, and J. M. Lane, “The biology of bone grafting," Journal of the American Academy of Orthopaedic Surgeons, vol. 13, no. 1, pp. 77-86, 2005.

[7] W. W. Tomford, "Transmission of disease through transplantation of musculoskeletal allografts," The Journal of Bone \& Joint Surgery, vol. 77, no. 11, pp. 1742-1754, 1995.

[8] C. T. Laurencin and S. F. El-Amin, "Xenotransplantation in orthopaedic surgery," Journal of the American Academy of Orthopaedic Surgeons, vol. 16, no. 1, pp. 4-8, 2008.

[9] G. Grabowski and C. A. Cornett, "Bone graft and bone graft substitutes in spine surgery: current concepts and controversies," Journal of the American Academy of Orthopaedic Surgeons, vol. 21, no. 1, pp. 51-60, 2013.

[10] J. F. Brandoff, J. S. Silber, and A. R. Vaccaro, "Contemporary alternatives to synthetic bone grafts for spine surgery," American Journal of Orthopedics, vol. 37, no. 8, pp. 410-414, 2008.

[11] B. D. Boyan, J. McMillan, C. H. Lohmann, D. M. Ranly, and Z. Schwartz, "Bone graft substitutes: basic information for successful clinical use with special focus on synthetic graft substitutes," in Bone Graft Substitutes, C. T. Laurencin, Ed., pp.
231-259, ASTM International, West Conshohocken, Pa, USA, 2003.

[12] C. Parrilla, N. Saulnier, C. Bernardini et al., "Undifferentiated human adipose tissue-derived stromal cells induce mandibular bone healing in rats," Archives of Otolaryngology - Head \& Neck Surgery, vol. 137, no. 5, pp. 463-470, 2011.

[13] E. Gómez-Barrena, P. Rosset, I. Müller et al., "Bone regeneration: stem cell therapies and clinical studies in orthopaedics and traumatology," Journal of Cellular and Molecular Medicine, vol. 15, no. 6, pp. 1266-1286, 2011.

[14] W. Lattanzi, E. Pola, G. Pecorini, C. A. Logroscino, and P. D. Robbins, "Gene therapy for in vivo bone formation: recent advances," European Review for Medical and Pharmacological Sciences, vol. 9, no. 3, pp. 167-174, 2005.

[15] S. T. Yoon and S. D. Boden, "Spine fusion by gene therapy," Gene Therapy, vol. 11, no. 4, pp. 360-367, 2004.

[16] S. G. Pneumaticos, G. K. Triantafyllopoulos, S. Chatziioannou, E. K. Basdra, and A. G. Papavassiliou, "Biomolecular strategies of bone augmentation in spinal surgery," Trends in Molecular Medicine, vol. 17, no. 4, pp. 215-222, 2011.

[17] B. N. Kimelman, I. Kallai, J. R. Lieberman, E. M. Schwarz, G. Pelled, and D. Gazit, "Gene therapy approaches to regenerating bone," Advanced Drug Delivery Reviews, vol. 64, no. 12, pp. 1320 1330, 2012.

[18] C. H. Evans, "Gene delivery to bone," Advanced Drug Delivery Reviews, vol. 64, no. 12, pp. 1331-1340, 2012.

[19] A. W. Baltzer and J. R. Lieberman, "Regional gene therapy to enhance bone repair," Gene Therapy, vol. 11, no. 4, pp. 344-350, 2004.

[20] W. Lattanzi, C. Parrilla, A. Fetoni et al., "Ex vivo-transduced autologous skin fibroblasts expressing human Lim mineralization protein-3 efficiently form new bone in animal models," Gene Therapy, vol. 15, no. 19, pp. 1330-1343, 2008.

[21] M. F. Pittenger, A. M. Mackay, S. C. Beck et al., "Multilineage potential of adult human mesenchymal stem cells," Science, vol. 284, no. 5411, pp. 143-147, 1999.

[22] N. Saulnier, W. Lattanzi, M. A. Puglisi et al., "Mesenchymal stromal cells multipotency and plasticity: induction toward the hepatic lineage," European Review for Medical and Pharmacological Sciences, vol. 13, supplement 1, pp. 71-78, 2009.

[23] E. M. Horwitz, B. K. Le, M. Dominici et al., "Clarification of the nomenclature for MSC: the international society for cellular therapy position statement," Cytotherapy, vol. 7, no. 5, pp. 393395, 2005.

[24] P. A. Zuk, M. Zhu, H. Mizuno et al., "Multilineage cells from human adipose tissue: implications for cell-based therapies," Tissue Engineering, vol. 7, no. 2, pp. 211-228, 2001.

[25] S. Díaz-Prado, E. Muiños-López, T. Hermida-Gómez et al., "Human amniotic membrane as an alternative source of stem cells for regenerative medicine," Differentiation, vol. 81, no. 3, pp. 162-171, 2011.

[26] B. C. De, F. Dell'accio, P. Tylzanowski, and F. P. Luyten, "Multipotent mesenchymal stem cells from adult human synovial membrane," Arthritis and Rheumatism, vol. 44, no. 8, pp. 19281942, 2001.

[27] A. Asakura, M. Komaki, and M. Rudnicki, "Muscle satellite cells are multipotential stem cells that exhibit myogenic, osteogenic, and adipogenic differentiation," Differentiation, vol. 68, no. 4-5, pp. 245-253, 2001.

[28] A. Erices, P. Conget, and J. J. Minguell, "Mesenchymal progenitor cells in human umbilical cord blood," British Journal of Haematology, vol. 109, no. 1, pp. 235-242, 2000. 
[29] M. Barba, F. Pirozzi, N. Saulnier et al., "Lim mineralization protein 3 induces the osteogenic differentiation of human amniotic fluid stromal cells through Kruppel-like factor-4 downregulation and further bone-specific gene expression," Journal of Biomedicine and Biotechnology, vol. 2012, Article ID 813894, 11 pages, 2012.

[30] N. Saulnier, A. C. Piscaglia, M. A. Puglisi et al., "Molecular mechanisms underlying human adipose tissue-derived stromal cells differentiation into a hepatocyte-like phenotype," Digestive and Liver Disease, vol. 42, no. 12, pp. 895-901, 2010.

[31] D. J. Prockop and J. Y. Oh, "Medical therapies with adult stem/progenitor cells (MSCs): a backward journey from dramatic results in vivo to the cellular and molecular explanations," Journal of Cellular Biochemistry, vol. 113, no. 5, pp. 1460-1469, 2012.

[32] A. Muraglia, R. Cancedda, and R. Quarto, "Clonal mesenchymal progenitors from human bone marrow differentiate in vitro according to a hierarchical model," Journal of Cell Science, vol. 113, part 7, pp. 1161-1166, 2000.

[33] E. M. Horwitz, D. J. Prockop, L. A. Fitzpatrick et al., "Transplantability and therapeutic effects of bone marrow-derived mesenchymal cells in children with osteogenesis imperfecta," Nature Medicine, vol. 5, no. 3, pp. 309-313, 1999.

[34] J. R. Chamberlain, U. Schwarze, P.-R. Wang et al., "Gene targeting in stem cells from Individuals with osteogenesis imperfecta," Science, vol. 303, no. 5661, pp. 1198-1201, 2004.

[35] A. Uccelli, L. Moretta, and V. Pistoia, "Mesenchymal stem cells in health and disease," Nature Reviews Immunology, vol. 8, no. 9, pp. 726-736, 2008.

[36] M. V. Risbud, I. M. Shapiro, A. Guttapalli et al., "Osteogenic potential of adult human stem cells of the lumbar vertebral body and the iliac crest," Spine, vol. 31, no. 1, pp. 83-89, 2006.

[37] R. F. McLain, J. E. Fleming, C. A. Boehm, and G. F. Muschler, "Aspiration of osteoprogenitor cells for augmenting spinal fusion: Comparison of progenitor cell concentrations from the vertebral body and iliac crest," Journal of Bone and Joint Surgery, vol. 87, no. 12, pp. 2655-2661, 2005.

[38] M. Zaim, S. Karaman, G. Cetin, and S. Isik, "Donor age and long-term culture affect differentiation and proliferation of human bone marrow mesenchymal stem cells," Annals of Hematology, vol. 91, no. 8, pp. 1175-1186, 2012.

[39] C. Cicione, S. Díaz-Prado, E. Muiños-López, T. HermidaGómez, and F. J. Blanco, "Molecular profile and cellular characterization of human bone marrow mesenchymal stem cells: donor influence on chondrogenesis," Differentiation, vol. 80, no. 2-3, pp. 155-165, 2010.

[40] H. Mizuno, M. Tobita, and A. C. Uysal, "Concise review: adipose-derived stem cells as a novel tool for future regenerative medicine," Stem Cells, vol. 30, no. 5, pp. 804-810, 2012.

[41] J. K. Fraser, I. Wulur, Z. Alfonso, and M. H. Hedrick, "Fat tissue: an underappreciated source of stem cells for biotechnology," Trends in Biotechnology, vol. 24, no. 4, pp. 150-154, 2006.

[42] B. A. Bunnell, M. Flaat, C. Gagliardi, B. Patel, and C. Ripoll, "Adipose-derived stem cells: isolation, expansion and differentiation," Methods, vol. 45, no. 2, pp. 115-120, 2008.

[43] P. A. Zuk, M. Zhu, P. Ashjian et al., "Human adipose tissue is a source of multipotent stem cells," Molecular Biology of the Cell, vol. 13, no. 12, pp. 4279-4295, 2002.

[44] W. Lattanzi, M. C. Geloso, N. Saulnier et al., "Neurotrophic features of human adipose tissue-derived stromal cells: in vitro and in vivo studies," Journal of Biomedicine and Biotechnology, vol. 2011, Article ID 468705, 9 pages, 2011.
[45] A. J. Katz, A. Tholpady, S. S. Tholpady, H. Shang, and R. C. Ogle, "Cell surface and transcriptional characterization of human adipose-derived adherent stromal (hADAS) cells," Stem Cells, vol. 23, no. 3, pp. 412-423, 2005.

[46] N. Saulnier, M. A. Puglisi, W. Lattanzi et al., "Gene profiling of bone marrow- and adipose tissue-derived stromal cells: a key role of Kruppel-like factor 4 in cell fate regulation," Cytotherapy, vol. 13, no. 3, pp. 329-340, 2011.

[47] J. M. Gimble, B. A. Bunnell, E. S. Chiu, and F. Guilak, "Concise review: adipose-derived stromal vascular fraction cells and stem cells: let's not get lost in translation," Stem Cells, vol. 29, no. 5, pp. 749-754, 2011.

[48] H. J. Harwood Jr., "The adipocyte as an endocrine organ in the regulation of metabolic homeostasis," Neuropharmacology, vol. 63, no. 1, pp. 57-75, 2012.

[49] J. Schmid, B. Wallkamm, C. H. Hämmerle, S. Gogolewski, and N. P. Lang, "The significance of angiogenesis in guided bone regeneration: a case report of a rabbit experiment," Clinical Oral Implants Research, vol. 8, no. 3, pp. 244-248, 1997.

[50] M. Barba, C. Cicione, C. Bernardini, F. Michetti, and W. Lattanzi, "Adipose-derived mesenchymal cells for bone regereneration: state of the art," BioMed Research International, vol. 2013, Article ID 416391, 11 pages, 2013.

[51] G. Giannicola, E. Ferrari, G. Citro et al., "Graft vascularization is a critical rate-limiting step in skeletal stem cell-mediated posterolateral spinal fusion," Journal of Tissue Engineering and Regenerative Medicine, vol. 4, no. 4, pp. 273-283, 2010.

[52] J.-W. Huang, S.-S. Lin, L.-H. Chen et al., "The use of fluorescence-labeled mesenchymal stem cells in poly(lactideco-glycolide)/hydroxyapatite/collagen hybrid graft as a bone substitute for posterolateral spinal fusion," Journal of Trauma, vol. 70, no. 6, pp. 1495-1502, 2011.

[53] S. A. Abbah, C. X. Lam, A. K. Ramruttun, J. C. Goh, and H.-K. Wong, "Fusion performance of low-dose recombinant human bone morphogenetic protein 2 and bone marrowderived multipotent stromal cells in biodegradable scaffolds: a comparative study in a large animal model of anterior lumbar interbody fusion," Spine, vol. 36, no. 21, pp. 1752-1759, 2011.

[54] M. Miyazaki, O. Sugiyama, J. Zou et al., "Comparison of lentiviral and adenoviral gene therapy for spinal fusion in rats," Spine, vol. 33, no. 13, pp. 1410-1417, 2008.

[55] P.-P. Vergroesen, R.-J. Kroeze, M. N. Helder, and T. H. Smit, "The use of poly(L-lactide-co-caprolactone) as a scaffold for adipose stem cells in bone tissue engineering: application in a spinal fusion model," Macromolecular Bioscience, vol. 11, no. 6, pp. 722-730, 2011.

[56] M. Miyazaki, P. A. Zuk, J. Zou et al., "Comparison of human mesenchymal stem cells derived from adipose tissue and bone marrow for ex vivo gene therapy in rat spinal fusion model," Spine, vol. 33, no. 8, pp. 863-869, 2008.

[57] M. J. Lopez, K. R. McIntosh, N. D. Spencer et al., "Acceleration of spinal fusion using syngeneic and allogeneic adult adipose derived stem cells in a rat model," Journal of Orthopaedic Research, vol. 27, no. 3, pp. 366-373, 2009.

[58] Q. Cui, X. Z. Ming, G. Balian, and G.-J. Wang, "Comparison of lumbar spine fusion using mixed and cloned marrow cells," Spine, vol. 26, no. 21, pp. 2305-2310, 2001.

[59] H. Orii, S. Sotome, J. Chen, J. Wang, and K. Shinomiya, "Betatricalcium phosphate (beta-TCP) graft combined with bone marrow stromal cells (MSCs) for posterolateral spine fusion," Journal of Medical and Dental Sciences, vol. 52, no. 1, pp. 51-57, 2005. 
[60] M. C. Kruyt, C. E. Wilson, J. D. de Bruijn et al., “The effect of cell-based bone tissue engineering in a goat transverse process model," Biomaterials, vol. 27, no. 29, pp. 5099-5106, 2006.

[61] H.-J. Kim, J.-B. Park, J. K. Lee et al., “Transplanted xenogenic bone marrow stem cells survive and generate new bone formation in the posterolateral lumbar spine of nonimmunosuppressed rabbits," European Spine Journal, vol. 17, no. 11, pp. 1515-1521, 2008.

[62] R. D. Rao, K. Gourab, V. B. Bagaria, V. B. Shidham, U. Metkar, and B. C. Cooley, "The effect of platelet-rich plasma and bone marrow on murine posterolateral lumbar spine arthrodesis with bone morphogenetic protein," Journal of Bone and Joint Surgery, vol. 91, no. 5, pp. 1199-1206, 2009.

[63] R. E. Geuze, H.-J. Prins, F. C. Öner et al., "Luciferase labeling for multipotent stromal cell tracking in spinal fusion versus ectopic bone tissue engineering in mice and rats," Tissue Engineering Part A, vol. 16, no. 11, pp. 3343-3351, 2010.

[64] M. C. Gupta, T. Theerajunyaporn, S. Maitra et al., "Efficacy of mesenchymal stem cell enriched grafts in an ovine posterolateral lumbar spine model," Spine, vol. 32, no. 7, pp. 720-726, 2007.

[65] T. Nakajima, H. Iizuka, S. Tsutsumi, M. Kayakabe, and K. Takagishi, "Evaluation of posterolateral spinal fusion using mesenchymal stem cells: differences with or without osteogenic differentiation," Spine, vol. 32, no. 22, pp. 2432-2436, 2007.

[66] K. R. McIntosh, M. J. Lopez, J. N. Borneman, N. D. Spencer, P. A. Anderson, and J. M. Gimble, "Immunogenicity of allogeneic adipose-derived stem cells in a rat spinal fusion model," Tissue Engineering Part A, vol. 15, no. 9, pp. 2677-2686, 2009.

[67] J. M. Gimble, B. A. Bunnell, E. S. Chiu, and F. Guilak, “Taking stem cells beyond discovery: a milestone in the reporting of regulatory requirements for cell therapy," Stem Cells and Development, vol. 20, no. 8, pp. 1295-1296, 2011.

[68] W. J. Jurgens, R. J. Kroeze, R. A. Bank, M. J. Ritt, and M. N. Helder, "Rapid attachment of adipose stromal cells on resorbable polymeric scaffolds facilitates the one-step surgical procedure for cartilage and bone tissue engineering purposes," Journal of Orthopaedic Research, vol. 29, no. 6, pp. 853-860, 2011.

[69] A. M. Müller, A. Mehrkens, D. J. Schäfer et al., "Towards an intraoperative engineering of osteogenic and vasculogenic grafts from the stromal vascular fraction of human adipose tissue," European Cells and Materials, vol. 19, pp. 127-135, 2010.

[70] R. M. Olabisi, Z. Lazard, M. H. Heggeness et al., "An injectable method for noninvasive spine fusion," Spine Journal, vol. 11, no. 6, pp. 545-556, 2011.

[71] C. Parrilla, W. Lattanzi, F. A. Rita, F. Bussu, E. Pola, and G. Paludetti, "Ex vivo gene therapy using autologous dermal fibroblasts expressing hLMP3 for rat mandibular bone regeneration," Head and Neck, vol. 32, no. 3, pp. 310-318, 2010.

[72] V. M. Betz, O. B. Betz, M. B. Harris, M. S. Vrahas, and C. H. Evans, "Bone tissue engineering and repair by gene therapy," Frontiers in Bioscience, vol. 13, pp. 833-841, 2008.

[73] W. Lattanzi and C. Bernardini, "Genes and molecular pathways of the osteogenic process," in Osteogenesis, Y. Lin, Ed., pp. 21-56, Intech, Rijeka, Croatia, 2011.

[74] J. S. Johnson, V. Meliton, W. K. Kim et al., "Novel oxysterols have pro-osteogenic and anti-adipogenic effects in vitro and induce spinal fusion in vivo," Journal of Cellular Biochemistry, vol. 112, no. 6, pp. 1673-1684, 2011.

[75] C. F. Hui, C. W. Chan, H. Y. Yeung et al., "Low-intensity pulsed ultrasound enhances posterior spinal fusion implanted with mesenchymal stem cells-calcium phosphate composite without bone grafting," Spine, vol. 36, no. 13, pp. 1010-1016, 2011.
[76] Y. Gan, K. Dai, P. Zhang, T. Tang, Z. Zhu, and J. Lu, “The clinical use of enriched bone marrow stem cells combined with porous beta-tricalcium phosphate in posterior spinal fusion," Biomaterials, vol. 29, no. 29, pp. 3973-3982, 2008.

[77] T.-S. Fu, S. W. Ueng, T.-T. Tsai, L.-H. Chen, S.-S. Lin, and W.-J. Chen, "Effect of hyperbaric oxygen on mesenchymal stem cells for lumbar fusion in vivo," BMC Musculoskeletal Disorders, vol. 11, article 52, 2010.

[78] K. D. Riew, N. M. Wright, S.-L. Cheng, L. V. Avioli, and J. Lou, "Induction of bone formation using a recombinant adenoviral vector carrying the human BMP-2 gene in a rabbit spinal fusion model," Calcified Tissue International, vol. 63, no. 4, pp. 357-360, 1998.

[79] S.-L. Cheng, J. Lou, N. M. Wright, C.-F. Lai, L. V. Avioli, and K. D. Riew, "In vitro and in vivo induction of bone formation using a recombinant adenoviral vector carrying the human BMP-2 gene," Calcified Tissue International, vol. 68, no. 2, pp. 87-94, 2001.

[80] C. Hidaka, K. Goshi, B. Rawlins, O. Boachie-Adjei, and R. G. Crystal, "Enhancement of spine fusion using combined gene therapy and tissue engineering BMP-7-expressing bone marrow cells and allograft bone," Spine, vol. 28, no. 18, pp. 2049-2057, 2003.

[81] M. Miyazaki, O. Sugiyama, B. Tow et al., "The effects of lentiviral gene therapy with bone morphogenetic protein-2-producing bone marrow cells on spinal fusion in rats," Journal of Spinal Disorders and Techniques, vol. 21, no. 5, pp. 372-379, 2008.

[82] T.-S. Fu, W.-J. Chen, L.-H. Chen, S.-S. Lin, S.-J. Liu, and S. W. Ueng, "Enhancement of posterolateral lumbar spine fusion using low-dose rhBMP-2 and cultured marrow stromal cells," Journal of Orthopaedic Research, vol. 27, no. 3, pp. 380-384, 2009.

[83] J. T. Douglas, A. A. Rivera, G. R. Lyons et al., “Ex vivo transfer of the Hoxc-8-interacting domain of Smadl by a tropismmodified adenoviral vector results in efficient bone formation in a rabbit model of spinal fusion," Journal of Spinal Disorders and Techniques, vol. 23, no. 1, pp. 63-73, 2010.

[84] Z.-B. Tang, J.-K. Cao, N. Wen et al., "Posterolateral spinal fusion with nano-hydroxyapatite-collagen/PLA composite and autologous adipose-derived mesenchymal stem cells in a rabbit model," Journal of Tissue Engineering and Regenerative Medicine, vol. 6, no. 4, pp. 325-336, 2012.

[85] J. Frantzén, A. Pälli, E. Kotilainen et al., "In vivo and in vitro study of a polylactide-fiber-reinforced $\beta$-tricalcium phosphate composite cage in an ovine anterior cervical intercorporal fusion model," International Journal of Biomaterials, vol. 2011, Article ID 109638, 11 pages, 2011.

[86] T. Schubert, S. Lafont, G. Beaurin et al., "Critical size bone defect reconstruction by an autologous $3 \mathrm{D}$ osteogenic-like tissue derived from differentiated adipose MSCs," Biomaterials, vol. 34, no. 18, pp. 4428-4438, 2013.

[87] W. K. Hsu, J. C. Wang, N. Q. Liu et al., "Stem cells from human fat as cellular delivery vehicles in an athymic rat posterolateral spine fusion model," Journal of Bone and Joint Surgery, vol. 90, no. 5, pp. 1043-1052, 2008.

[88] D. Sheyn, G. Pelled, Y. Zilberman et al., "Nonvirally engineered porcine adipose tissue-derived stem cells: use in posterior spinal fusion," Stem Cells, vol. 26, no. 4, pp. 1056-1064, 2008.

[89] D. Sheyn, I. Kallai, W. Tawackoli et al., "Gene-modified adult stem cells regenerate vertebral bone defect in a rat model," Molecular Pharmaceutics, vol. 8, no. 5, pp. 1592-1601, 2011. 
[90] K. Miyazono, S. Maeda, and T. Imamura, "BMP receptor signaling: transcriptional targets, regulation of signals, and signaling cross-talk," Cytokine and Growth Factor Reviews, vol. 16, no. 3, pp. 251-263, 2005.

[91] X. Wu, W. Shi, and X. Cao, "Multiplicity of BMP signaling in skeletal development," Annals of the New York Academy of Sciences, vol. 1116, pp. 29-49, 2007.

[92] T. Katagiri, A. Yamaguchi, M. Komaki et al., "Bone morphogenetic protein-2 converts the differentiation pathway of $\mathrm{C} 2 \mathrm{C} 12$ myoblasts into the osteoblast lineage," Journal of Cell Biology, vol. 127, no. 6, pp. 1755-1766, 1994.

[93] M. Okamoto, J. Murai, H. Yoshikawa, and N. Tsumaki, "Bone morphogenetic proteins in bone stimulate osteoclasts and osteoblasts during bone development," Journal of Bone and Mineral Research, vol. 21, no. 7, pp. 1022-1033, 2006.

[94] L. Pham, K. Beyer, E. D. Jensen et al., "Bone morphogenetic protein 2 signaling in osteoclasts is negatively regulated by the BMP antagonist, twisted gastrulation," Journal of Cellular Biochemistry, vol. 112, no. 3, pp. 793-803, 2011.

[95] M. E. Bahamonde and K. M. Lyons, "BMP3: to be or not to be a BMP," Journal of Bone and Joint Surgery, vol. 83, supplement 1, pp. S56-S62, 2001.

[96] E. Canalis, A. N. Economides, and E. Gazzerro, "Bone morphogenetic proteins, their antagonists, and the skeleton," Endocrine Reviews, vol. 24, no. 2, pp. 218-235, 2003.

[97] E. Balint, D. Lapointe, H. Drissi et al., "Phenotype discovery by gene expression profiling: mapping of biological processes linked to BMP-2-mediated osteoblast differentiation," Journal of Cellular Biochemistry, vol. 89, no. 4, pp. 401-426, 2003.

[98] C. Evans, "Gene therapy for the regeneration of bone," Injury, vol. 42, no. 6, pp. 599-604, 2011.

[99] M. H. Alaoui-Ismaili and D. Falb, "Design of second generation therapeutic recombinant bone morphogenetic proteins," Cytokine and Growth Factor Reviews, vol. 20, no. 5, pp. 501-507, 2009.

[100] B. Peterson, R. Iglesias, J. Zhang, J. C. Wang, and J. R. Lieberman, "Genetically modified human derived bone marrow cells for posterolateral lumbar spine fusion in athymic rats: beyond conventional autologous bone grafting," Spine, vol. 30, no. 3, pp. 283-289, 2005.

[101] T. D. Alden, D. D. Pittman, E. J. Beres et al., "Percutaneous spinal fusion using bone morphogenetic protein-2 gene therapy," Journal of Neurosurgery, vol. 90, no. 1, pp. 109-114, 1999.

[102] J. R. Lieberman, A. Daluiski, S. Stevenson et al., "The effect of regional gene therapy with bone morphogenetic protein2- producing bone-marrow cells on the repair of segmental femoral defects in rats," Journal of Bone and Joint Surgery, vol. 81, no. 7, pp. 905-917, 1999.

[103] J. C. Wang, L. E. Kanim, S. Yoo, P. A. Campbell, A. J. Berk, and J. R. Lieberman, "Effect of regional gene therapy with bone morphogenetic protein-2-producing bone marrow cells on spinal fusion in rats," Journal of Bone and Joint Surgery, vol. 85, no. 5, pp. 905-911, 2003.

[104] C. J. Hwang, A. R. Vaccaro, J. P. Lawrence et al., "Immunogenicity of bone morphogenetic proteins," Journal of Neurosurgery, vol. 10, no. 5, pp. 443-451, 2009.

[105] G. A. Helm, T. D. Alden, E. J. Beres et al., "Use of bone morphogenetic protein-9 gene therapy to induce spinal arthrodesis in the rodent," Journal of Neurosurgery, vol. 92, no. 2, pp. 191-196, 2000 .
[106] J. Zhao, D.-Y. Zhao, A.-G. Shen et al., "Promoting lumbar spinal fusion by adenovirus-mediated bone morphogenetic protein- 4 gene therapy," Chinese Journal of Traumatology, vol. 10, no. 2, pp. 72-76, 2007.

[107] J. J. Laurent, K. M. Webb, E. J. Beres et al., “The use of bone morphogenetic protein -6 gene therapy for percutaneous spinal fusion in rabbits," Journal of Neurosurgery, vol. 1, no. 1, pp. 9094, 2004.

[108] R. K. Siu, S. S. Lu, W. Li et al., "Nell-1 protein promotes bone formation in a sheep spinal fusion model," Tissue Engineering Part A, vol. 17, no. 7-8, pp. 1123-1135, 2011.

[109] S. S. Lu, X. Zhang, C. Soo et al., "The osteoinductive properties of Nell-1 in a rat spinal fusion model," Spine Journal, vol. 7, no. 1, pp. 50-60, 2007.

[110] H.-S. Kim, M. Viggeswarapu, S. D. Boden et al., "Overcoming the immune response to permit ex vivo gene therapy for spine fusion with human type 5 adenoviral delivery of the LIM mineralization protein-1 cDNA," Spine, vol. 28, no. 3, pp. 219226, 2003.

[111] K. Ting, H. Vastardis, J. B. Mulliken et al., "Human NELL-1 expressed in unilateral coronal synostosis," Journal of Bone and Mineral Research, vol. 14, no. 1, pp. 80-89, 1999.

[112] T. Aghaloo, C. M. Cowan, Y.-F. Chou et al., "Nell-1-induced bone regeneration in calvarial defects," American Journal of Pathology, vol. 169, no. 3, pp. 903-915, 2006.

[113] S. D. Boden, L. Titus, G. Hair et al., "Lumbar spine fusion by local gene therapy with a cDNA encoding a novel osteoinductive protein (LMP-1)," Spine, vol. 23, no. 23, pp. 2486-2492, 1998.

[114] C. Bernardini, N. Saulnier, C. Parrilla et al., "Early transcriptional events during osteogenic differentiation of human bone marrow stromal cells induced by Lim mineralization protein 3," Gene Expression, vol. 15, no. 1, pp. 27-42, 2010.

[115] S. T. Yoon, J. S. Park, K. S. Kim et al., "ISSLS prize winner: LMP-1 upregulates intervertebral disc cell production of proteoglycans and BMPs in vitro and in vivo," Spine, vol. 29, no. 23, pp. 26032611, 2004.

[116] A. Minamide, S. D. Boden, M. Viggeswarapu, G. A. Hair, C. Oliver, and L. Titus, "Mechanism of bone formation with gene transfer of the cDNA encoding for the intracellular protein LMP-1," Journal of Bone and Joint Surgery, vol. 85, no. 6, pp. 1030-1039, 2003.

[117] C. A. Strohbach, C. H. Rundle, J. E. Wergedal et al., "LMP-1 retroviral gene therapy influences osteoblast differentiation and fracture repair: a preliminary study," Calcified Tissue International, vol. 83, no. 3, pp. 202-211, 2008.

[118] M. Viggeswarapu, S. D. Boden, Y. Liu et al., "Adenoviral delivery of LIM mineralization protein-1 induces new-bone formation in vitro and in vivo," Journal of Bone and Joint Surgery, vol. 83, no. 3, pp. 364-376, 2001.

[119] X. Wang, F. Cui, V. Madhu, A. S. Dighe, G. Balian, and Q. Cui, "Combined VEGF and LMP-1 delivery enhances osteoprogenitor cell differentiation and ectopic bone formation," Growth Factors, vol. 29, no. 1, pp. 36-48, 2011.

[120] W. Lattanzi, M. Barba, F. Novegno et al., "Lim mineralization protein is involved in the premature calvarial ossification in sporadic craniosynostoses," Bone, vol. 52, no. 1, pp. 474-484, 2013. 


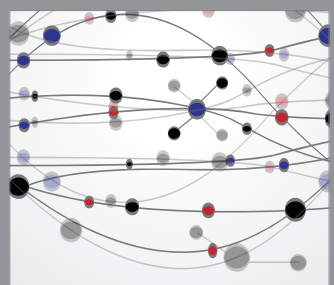

The Scientific World Journal
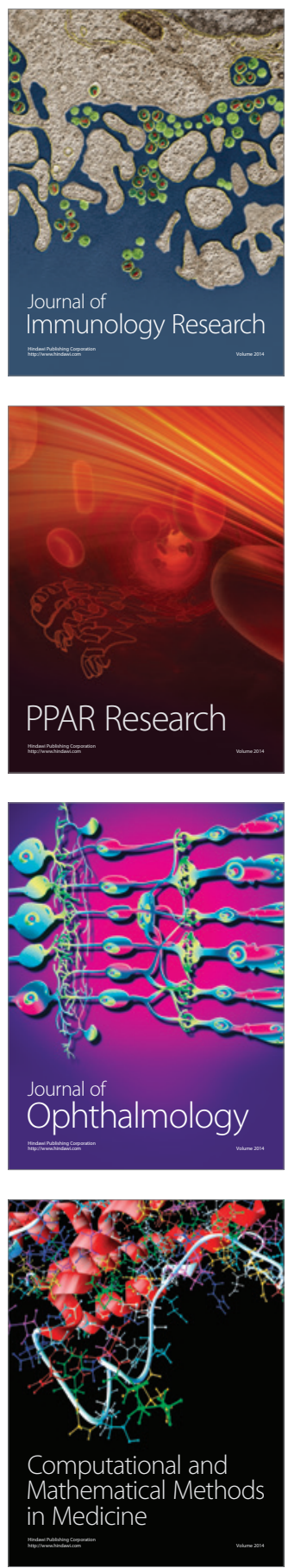

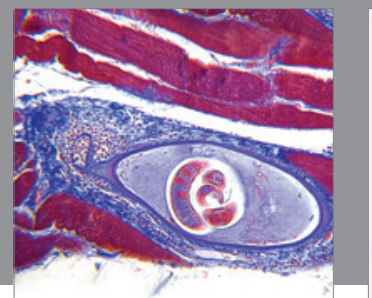

Gastroenterology

Research and Practice
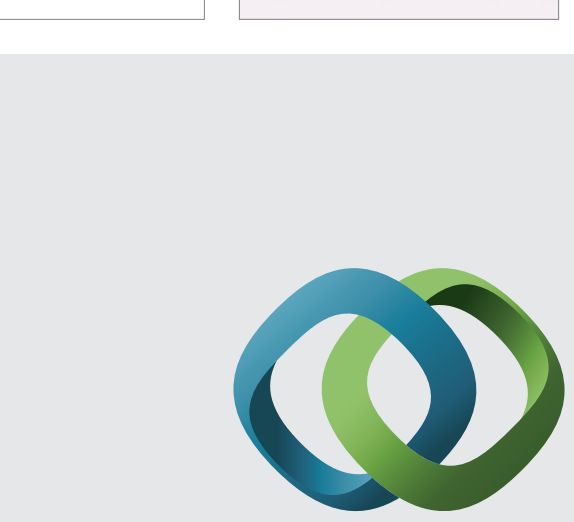

\section{Hindawi}

Submit your manuscripts at

http://www.hindawi.com
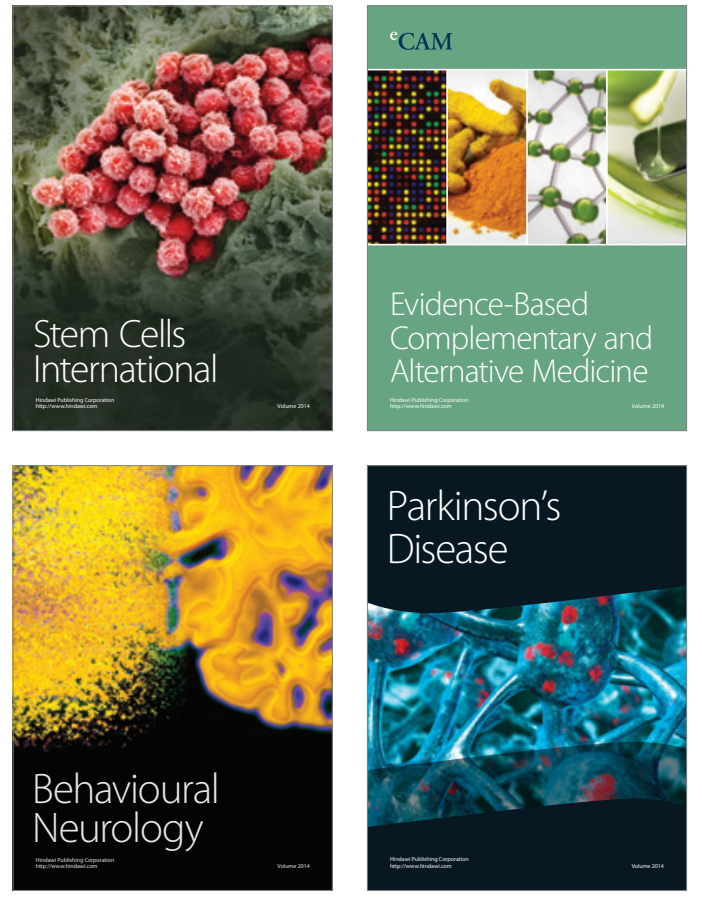
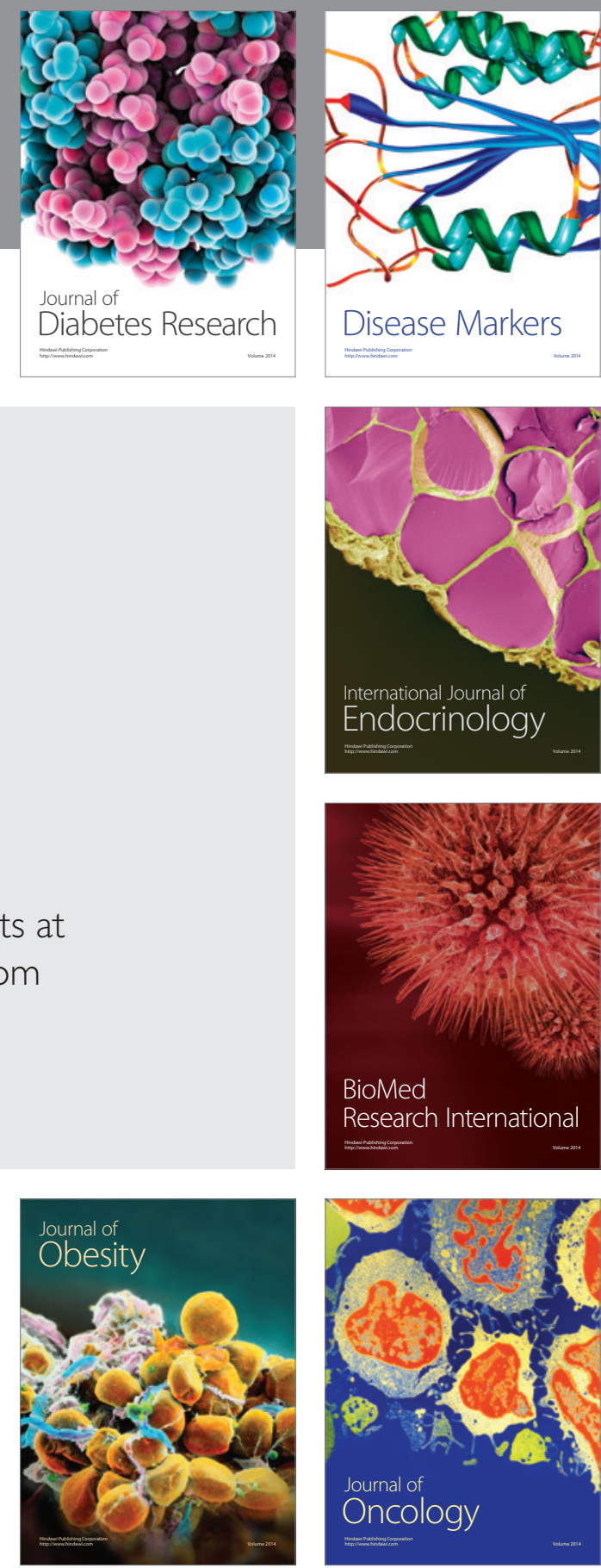

Disease Markers
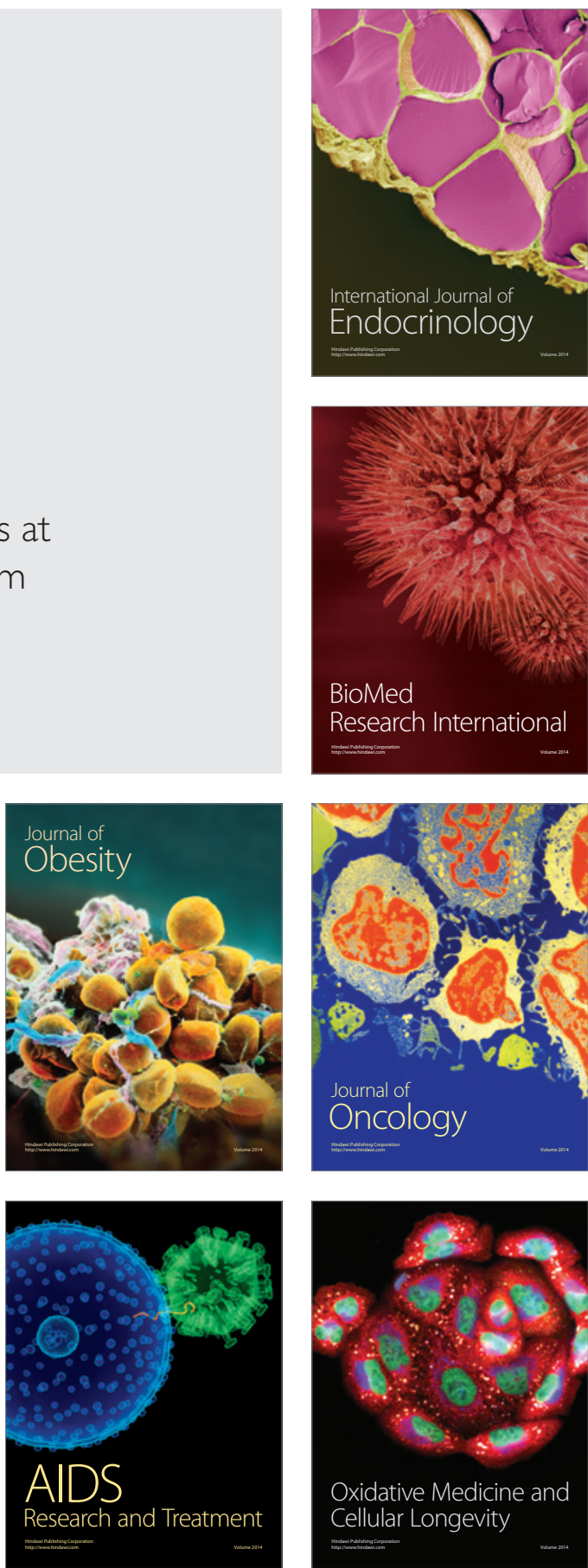